\title{
NEOCOLONIALIDADE NA INTERNACIONALIZAÇÃO DA EDUCAÇÃO SUPERIOR
}

\section{Marilia Ribas Machado* Mario Cesar Barreto Moraes**}

\begin{abstract}
Resumo: Este artigo tem por objetivo verificar se o Programa Estudante-Convênio de Pós-Graduação (PEC-PG) pode ser caracterizado como um programa que segue uma epistemologia neocolonial de controle e dominação frente aos países com os quais o Brasil possui acordos de cooperação educacional. A partir deste estudo foi possível observar que a educação muitas vezes é utilizada como instrumento de dominação e controle entre os países, de forma que reproduz práticas neocoloniais entre os países.
\end{abstract}

Palavras-chave: Educação Superior; Internacionalização; Neocolonialidade; PEC-PG.

Resumen: Este artículo tiene como objetivo verificar si el Programa de Acuerdo de Estudiantes y Graduados (PEC-PG) puede caracterizarse como un programa que sigue una epistemología neocolonial de control y dominación con respecto a los países con los que Brasil tiene acuerdos de cooperación educativa. A partir de este estudio, fue posible observar que la educación a menudo se usa como un instrumento de dominación y control entre países, de una manera que reproduce las prácticas neocoloniales entre países.

Palabras clave: Educación Superior; Internacionalización; Neocolonialidad; PEC-PG.

\section{Introdução}

Historicamente, a educação e a internacionalização da educação superior no Brasil estão fortemente atreladas ao Estado (como responsável pela definição de políticas, pelo financiamento e regulação) e a participação das universidades públicas $e$ institutos de pesquisa por ele mantidos (LIMA; CONTEL, 2009).

O processo de internacionalização vivenciado pelo Brasil nos anos de 1970 foi formulado a partir de políticas públicas voltadas para a consolidação do sistema nacio-

\footnotetext{
* Mestre em Administração Universitária pela Universidade Federal de Santa Catarina (UFSC); Doutoranda em Administração pela Universidade do Estado de Santa Catarina (UDESC/ESAG). Endereço eletrônico: marilia.ribas9@gmail.com.

** Doutor em Engenharia de Produção pela Universidade Federal de Santa Catarina. Conselheiro do Conselho Estadual de Educação do Estado de Santa Catarina (CEE-SC). Professor titular da Universidade do Estado de Santa Catarina (UDESC/ESAG). Endereço eletrônico: mcbmstrategos@gmail.com.
}

nal de educação superior. Havia também o interesse em formar pesquisadores e profissionais com conhecimentos requeridos pelo projeto de modernização das instituições públicas e da diversificação da indústria nacional (LIMA; CONTEL, 2009).

O panorama da educação internacional, a proporção do aumento das demandas por educação internacional resultando em mobilidade estudantil permanecem desconhecidos, mas o movimento de programas $e$ provedores de educação através das fronteiras nacionais crescem significativamente (ALTBACH; KNIGHT, 2007). A mobilidade acadêmica internacional favorece sistemas educacionais bem desenvolvidos $e$ instituições, compondo assim desigualdades. No âmbito social, a globalização é a responsável por concentrar riqueza, conhecimento e poder naqueles que já possuem esses elementos. (ALTBACH; KNIGHT, 2007). 
As desigualdades que ocorrem tanto no aspecto social e educacional também ocorre no âmbito da internacionalização da educação entre os países mais desenvolvidos em relação aos países menos desenvolvidos. Nesse sentido, a literatura reconhece algumas manifestações do processo de internacionalização da educação como expressões de uma espécie de colonialismo moderno (LIMA; MARANHÃO, 2011).

Os países desenvolvidos, os países do "Norte" são os responsáveis por controlar em grande parte o processo da internacionalização da educação (ALTBACH; KNIGHT, 2007). Essas nações fornecem uma preparação educacional eficaz para estudantes universitários, como internacionalização do currículo, acompanhamento do movimento físico de estudantes, programas, provedores, $e$ pessoal acadêmico através das fronteiras (ALTBACH; KNIGHT, 2007).

Em contrapartida, embora os países em desenvolvimento produzam um pequeno fluxo estudantil mundial, eles hospedam um número significativo de estudantes internacionais. O objetivo destes países é atrair estudantes estrangeiros para suas universidades para melhorar a qualidade e a composição cultural do corpo discente, ganhar prestígio $e$ receber rendimentos (ALTBACH; KNIGHT, 2007).

Porém, mesmo nas relações que acontecem entre países subdesenvolvidos há uma relação de dependência evidenciada na educação superior mundial contemporânea. O Brasil, enquanto país subdesenvolvido, deve procurar não reproduzir práticas com viés imperialista ou neocolonial, de contínua dependência econômica, política, cultural ou educacional com os países os quais mantém acordos de cooperação (LEAL; MORAES, 2018). Evitando, inclusive, uma formação deficitária, ou uma semiformação entre os estudantes, uma vez que as demandas dos acadêmicos destes países beneficiários dificilmente são consideradas (LIMA; MARANHÃO, 2011).

Desta maneira, torna-se indispensável conhecer a realidade, mensurar seus resultados e repensar seus impactos também na perspectiva do outro que é beneficiário da cooperação prestada (LEAL; MORAES, 2018; MILANI, 2012). No sentido de buscar não reproduzir relações que se caracterizem pela produção coletiva e pela troca de conhecimento para o desenvolvimento econômico-social de ambas as partes (LIMA; MARANHÃO, 2011).

Nesse sentido, o objetivo do artigo é verificar se o Programa Estudante-Convênio de Pós-Graduação pode ser caracterizado como um programa que segue uma política neocolonial de controle e dominação frente aos países com os quais o Brasil possui acordos de cooperação.

\section{Internacionalização da educação}

As insuficientes reservas de conhecimento nos países em desenvolvimento, representadas por deficiências em mão-deobra especializada e pela fragilidade organizacional e institucional, além dos sistemas de educação de países que possuem sistemas educacionais consolidados nutrem interesse de acolher estudantes ao mesmo tempo que os países periféricos necessitam enviar parte dos acadêmicos para estudar em universidades mundialmente reconhecidas (PUENTE, 2010; SANTOS, 2006). 
Apesar da internacionalização de estudantes, em particular a mobilidade acadêmica, valorizar a multiculturalidade e o multilinguismo, o que se percebe é que as políticas de internacionalização das universidades e dos governos têm favorecendo a subordinação de uma cultura econômica e politicamente mais fraca à dominante ao invés de proporcionar o desenvolvimento de um multiculturalismo tal como seu legítimo propósito (LIMA; MARANHÃO, 2011).

Em virtude disso, diversas medidas são adotadas para manutenção de estruturas dominantes na educação superior, tais como a padronização dos serviços oferecidos, a arquitetura dos cursos, o desenho dos currículos, a formulação do programa de ensino, o idioma adotado. Continuando desta forma, por perpetuar a hegemonia que países mais desenvolvidos e com estruturas de educação mais consolidadas exercem sob os demais. Pode-se dizer, neste sentido, que a internacionalização da educação funciona como uma ferramenta que a indústria cultural utiliza em favor da manutenção do status quo (LIMA; MARANHÃO, 2011).

Embora o domínio da internacionalização da educação seja um fenômeno predominante dos países desenvolvidos sob os países subdesenvolvidos, ela não é um "privilégio dos países desenvolvidos" (PUENTE, 2010, p. 55). O Brasil, é possível observar, que mesmo sendo um país em desenvolvimento adota os mesmos comportamentos de países desenvolvidos em relação aos demais países, seguindo a mesma lógica de reprodução neocolonial. Dessa forma, ao contrário do que se imaginava, as relações de dominação e controle também estão presentes nas relações entre países em desenvolvimen- to, pois da mesma forma eles estabelecem contrapartidas econômicas na cooperação prestada a outros países com grau de desenvolvimento relativamente inferior (MILANI, 2012).

Seguindo esta perspectiva, a Cooperação Técnica para o Desenvolvimento no Brasil identificou uma forma de reforçar suas aproximações com países da América Latina e com países africanos de língua portuguesa, inclusive como forma de exercer liderança entre os demais. Houve, na origem da cooperação técnica do Brasil uma conjugação de elementos motivacionais geoestratégicos e geopolíticos (vizinhança, entorno geográfico) com fatores decorrentes de vínculos históricos e culturais (PUENTE, 2010).

Convém observar que, embora a cooperação internacional signifique trabalhar em conjunto, para Silva (2007, p. 7) "a colaboração é não equitativa e assimétrica, o que implica a existência de um ator principal, responsável pelo programa e proprietário dos resultados mais interessantes do ponto de vista de aplicação estratégica, industrial e comercial, enquanto os outros são apenas coadjuvantes". Da mesma maneira, verificase que a internacionalização da educação desenvolvida pelo Brasil em relação aos países de seu entorno, dificilmente irá colaborar para a promoção do multiculturalismo, expresso pela integração baseada no respeito às diferentes culturas, etnias, religiões (LIMA; MARANHÃO, 2011).

A despeito desta relação entre países em desenvolvimento, é difícil imaginar que se consiga reproduzir na prática, além do discurso, a igualdade entre as partes (LEAL; MORAES, 2018). Muitas vezes, há outras motivações, nem sempre admitidas, "como 
interesses políticos, geoestratégicos e de segurança nacional, ou econômicos e comerciais" (PUENTE, 2010 p. 51). De modo que existirá, quase sempre, a tendência de se reproduzir, ainda que em menor escala, algum tipo de verticalidade na inter-relação entre colonizador e colonizado (PUENTE, 2010).

\section{Neocolonialidade}

A colonialidade é um dos elementos constitutivos do padrão mundial de poder capitalista. Constitui-se na imposição de uma classificação racial/étnica da população do mundo como padrão de poder e opera em cada um dos planos, âmbitos e dimensões materiais e subjetivas, da existência social cotidiana e da escala social. Origina-se $e$ mundializa-se a partir da América (QUIJANO, 2000).

Sob "sua condição de centro do capitalismo mundial, a Europa não somente tinha o controle do mercado mundial, mas pode impor seu domínio colonial sobre todas as regiões e populações do planeta" (QUIJANO, 2005, p. 121). O autor ainda argumenta, essa condição desenvolveu nos europeus um traço comum a todos os dominadores coloniais e imperiais da história, o etnocentrismo. Mas no caso europeu esse traço tinha um fundamento e uma justificação peculiar: a classificação racial da população do mundo depois da América (QUIJANO, 2005).

Para o autor Quijano (2000, p. 342), "raça, gênero e trabalho foram as três linhas principais de classificação que constituíram a formação do capitalismo mundial moderno no século XVI". E tendo em vista que as relações sociais que se estavam configurando eram relações de controle, tais identidades foram associadas às hierarquias, lugares $e$ papeis sociais correspondentes, e, consequentemente, ao padrão de dominação que se impunha (QUIJANO, 2005).

Essas relações de dominação e controle não eram restritas somente a europeus. As relações intersubjetivas e culturais entre a Europa Ocidental, e o restante do mundo, foram codificadas em novas categorias: Oriente-Ocidente, primitivo-civilizado, míticocientífico, irracional-racional, tradicionalmoderno. A elaboração intelectual do processo de modernidade produziu um modo de produzir conhecimento que demonstram o caráter do padrão mundial de poder: colonial, moderno, capitalista e eurocentrado. Esse modo de produzir conhecimento é o que se reconhece como eurocentrismo (QUIJANO, 2005).

O eurocentrismo trata-se de uma perspectiva de conhecimento que se torna mundialmente hegemônica colonizando e sobrepondo-se a todas as demais, prévias ou diferentes, e a seus respectivos saberes concretos, tanto na Europa como no resto do mundo (QUIJANO, 2005). Esta perspectiva de conhecimento implica supor que existe uma inteligência superior que se propõe a ensinar algo a uma inteligência inferior (RANCIÈRE, 2011). O autor ainda afirma que, a experiência pedagógica está estruturada na desigualdade, pois aquele que ensina está em uma posição superior daquele que aprende e o aprendiz estará sempre preso à sua ignorância, pois o professor sempre terá algo mais a lhe ensinar (RANCIÈRE, 2011).

Dessa maneira, as estratégias de preservação e de expansão do poder das estruturas hegemônicas foram se aprimorando $e$ se desenvolvendo em vários campos de do- 
mínios e utilizam inclusive, diversas táticas $e$ instrumentos (GUIMARÃES, 1998). Neste entendimento, verifica-se que as "relações de colonialidade nas esferas econômicas $e$ políticas não findaram com a destruição do colonialismo" (BALLESTRIN, 2013, p. 99). Nesta mesma perspectiva, Fanon (2005, p. 83), argumenta que com as independências "o martelamento da artilharia, a política da terra arrasada deu lugar à sujeição econômica”. Assim, muitas das nações da África, da Ásia e da América do Sul que adquiriram independência política no século XX se mantiveram economicamente dependentes (FANON, 2005; NAYAR, 2015).

No campo da educação, as pesquisas reproduzem a perspectiva Norte-Sul, de maneira que o Sul depende do que é produzido no Norte. A influência da globalização, refletida nas formas de "internacionalização ativa" (nos casos dos países que integram o núcleo do capitalismo mundial) e de "internacionalização passiva" (no caso dos países em condição histórica de dependência) (LIMA, MARANHÃO, 2011, p.16). Ainda no campo da internacionalização da educação, Guimarães (1998) complementa ao afirmar que "os programas de difusão cultural, de bolsas de estudo, de pesquisadores visitantes e de formadores de opinião também são instrumentos utilizados amplamente pelos países que integram o centro dessas estruturas".

Também é natural que ocorra, não em todos, mas em um grande número dos indivíduos que participam de tais programas, venham a desenvolver sentimentos de simpatia em relação ao estilo de vida, ao modo de ver o mundo dos países doadores (GUIMARÃES, 1998). Nesse sentido, observa-se que, se por um lado o vínculo formal entre nações colonizadoras e colonizadas se extinguiu, por outro, foi substituído por práticas imperialistas que determinam a contínua dependência econômica, política e cultural entre os países (LEAL; MORAES, 2018b).

\section{Programa de Estudantes-Convênio de Pós- Graduação (PEC-PG) \\ O Programa de Estudantes-Convênio} de Pós-Graduação (PEC-PG), criado oficialmente em 1981, oferece bolsas de estudo para estudantes de países em desenvolvimento com os quais o Brasil possui acordo de cooperação cultural, educacional ou científico-tecnológica para formação em cursos de pós-graduação strictu sensu (mestrado $e$ doutorado) em Instituições de Ensino Superior (IES) brasileiras. Os principais objetivos de programas de bolsas de estudos póssecundários concedidas a alunos internacionais é promover o desenvolvimento dos países de origem dos beneficiários. Esse é um dos objetivos da cooperação educacional brasileira e consta explicitamente no Manual do PEC-PG (BRASIL, 2020a) que determina que o programa tem o objetivo de "(...) contribuir para a formação de recursos humanos, por meio da concessão de bolsas de mestrado e doutorado para a realização de estudos em IES brasileiras (...)", com o intuito de “(...) aprimorar a qualificação de professores universitários pesquisadores, profissionais e graduados do ensino superior, visando sua contribuição para o desenvolvimento de seus países" (BRASIL, 2020b).

O PEC-PG teve seu primeiro protocolo assinado em 1981 e atualizado em 2006. Ao longo da última década, foram selecionados mais de 1.600 estudantes de pós-graduação. 
Cerca de $75 \%$ das candidaturas vem de países das Américas, com destaque para Colômbia, Peru e Argentina. Os países africanos respondem por cerca de $20 \%$ das candidaturas, com destaque para Moçambique, Cabo Verde e Angola. Entre os países asiáticos, responsáveis por cerca de $5 \%$ das candidaturas, o Timor-Leste conta com maior número de inscritos e de selecionados. Atualmente, participam do PEC-PG 60 países, sendo 26 na África, 25 na América e Caribe e 9 na Ásia (BRASIL, 2020c)

Apesar de se tratar de um programa de cooperação entre países em desenvolvimento, tal como preconiza a teorias de Cooperação Sul-Sul, tanto o documento de criação do PEC-PG (1982) quanto o protocolo publicado em 2006 apresentam poucas características de cooperação horizontal com os países em vias de desenvolvimento. O decreto restringe-se a estabelecer obrigatoriedades, condicionalidades e compromissos bastante rígidos que os estudantes devem atender, a saber:

1) ser cidadão dos países em desenvolvimento com os quais o Brasil mantenha Acordo - de Cooperação Educacional, Cultural ou de Ciência e Tecnologia; 2) não ser portador de visto permanente no Brasil; 3) é vedada a participação de cidadãos brasileiros, ainda que binacionais, assim como de candidatos cujo genitor ou genitora seja brasileiro; 4) ser portador do Certificado de Proficiência em Língua Portuguesa para Estrangeiros (CELPE-Bras), se oriundo de país não lusófono, ou carta do orientador brasileiro pela qual se responsabiliza pela proficiência em português do candidato [...] 7) apresentar duas cartas de recomendação de professores, pesquisadores ou de pessoas de reconhecida competência na área; 8) apresentar currículo em língua portuguesa; 9) apresentar plano de trabalho, em língua portuguesa; 10) apresentar certidão de nascimento ou documento de identidade de seus genitores (BRASIL, 2020b).

Algumas das condicionalidades que os estudantes devem atender são:

1) será dada prioridade aos candidatos que comprovarem ter vínculo empregatício no país de origem. No caso de vínculo com Instituição de Ensino Superior, esses candidatos deverão apresentar a devida comprovação; 2) a documentação relacionada deverá ser apresentada à Missão Diplomática brasileira no país de origem ou de residência fixa do candidato, independentemente de onde ele estiver, inclusive via correio tradicional; 3) todos os formulários anexos [...] deverão ser preenchidos em língua portuguesa; 4) o candidato que tiver concluído o curso superior no Brasil sob o amparo do Programa de Estudantes-Convênio de Graduação (PEC-G) somente poderá participar do PEC-PG caso comprove ter permanecido no país de origem por, pelo menos, dois anos após ter obtido o diploma brasileiro. Casos excepcionais poderão ser acolhidos a critério do Grupo de Supervisão [...] (BRASIL, 2020b).

Alguns dos compromissos que os estudantes devem cumprir:

Executar o plano de atividades aprovado no âmbito do Programa; Assinar o termo de compromisso obrigando-se a cumprir as metas pactuadas pela IES no projeto $e$ a devolver à agência financiadora eventuais benefícios recebidos indevidamente; Apresentar formalmente os resultados parciais e finais de seu trabalho, por meio de relatórios de 
atividades anuais, além de pareceres do orientador e histórico escolar, a critério da agência financiadora; Submeter-se às exigências do Programa PEC-PG, inclusive as incluídas no presente manual, às disposições regimentais da IES em que estiver matriculado, e às normas da agência financiadora concessora de sua bolsa; Manter atualizado, junto às autoridades competentes, o visto temporário, sob pena de suspensão temporária da bolsa, com possibilidade de desligamento do programa; Fazer referência ao apoio recebido pela respectiva agência financiadora nos trabalhos publicados em decorrência das atividades desenvolvidas no âmbito do PEC-PG, com as seguintes expressões [...] Se publicado individualmente: "O presente trabalho foi realizado com o apoio do Programa Estudantes-Convênio de Pós-Graduação - PEC-PG, da CA$\mathrm{PES} / \mathrm{CNPq}$ - Brasil". Se publicado em coautoria: "Bolsista do Programa Estudantes-Convênio de PósGraduação - PEC-PG, da CA$\mathrm{PES} / \mathrm{CNPq}$ - Brasil" (BRASIL, 2020b).

O restante dos documentos acerca do PEC-PG não menciona quaisquer indicativos de cooperação ou contrapartidas, pelos quais os países que são responsáveis por encaminhar os estudantes devem cumprir ou desenvolver no Brasil. Os decretos se limitam somente a estabelecer condicionalidades, obrigatoriedades e prerrogativas que todos os estudantes de fora devem cumprir no Brasil, e caso não se façam cumprir algumas das prerrogativas, os estudantes estão sujeitos a sanções junto a Polícia Federal.

\section{O PEC-PG como uma Política de Controle Neocolonial}

Os estudantes estrangeiros que ingressam no Brasil o fazem por meio de um visto de estudo já concedido pelo Ministério das Relações Exteriores e chegam a partir de um uma relação previamente estabelecida acordada entre os países, com regras, condições e outras normatizações.

A apresentação à Polícia Federal é uma prática constante aos alunos do PECPG, pois precisam tratar de assuntos e exigências legais. Os cumprimentos dessas obrigações são vistos pelos estudantes como uma situação tensa envolta por uma sensação de ansiedade. Em geral, os alunos em nível de graduação precisam se apresentar a cada ano, e os de pós-graduação, a cada dois anos. Esse prazo de um ano pode ser prorrogado por igual período até o final do curso (NOGUEIRA, 2013).

As leis migratórias estabelecem que o estrangeiro registre seu domicílio, o que demonstra ser um elemento discriminatório, uma necessidade de colocar a vida do estrangeiro sob o controle do Estado, demonstrando a necessidade de conhecer e controlar os sujeitos que habitam seu território, o que remete a uma forma de controle sobre os corpos dos indivíduos (ETCHEVERRY, 2016).

Além do controle exercido pelo estado via estruturas de autoridade, atualmente a dominação e o controle são exercidos também de maneiras mais discretas, através das esferas científicas, culturais e educacionais. $\mathrm{O}$ controle dos países é frequentemente acompanhado por um imperialismo cultural, e científico, que constitui-se como a face mais visível do neocolonialismo (NAYAR, 2015). Conforme corrobora Quijano (2002) hoje em dia, os controles exercidos pelos países 
são encobertos por estruturas institucionalizadas de autoridade coletiva ou pública $e$ "legitimadas" por ideologias constitutivas das relações intersubjetivas entre os vários setores de interesse e de identidade da população.

Em vista disso, a educação pode ser representada como uma área na qual as políticas públicas nacionais podem se projetar mundialmente, levando soluções brasileiras a problemas enfrentados por diversos países, sobretudo os mais pobres. Convém destacar, contudo, que tais soluções respondem mais a interesses comerciais, ou influências político-estratégicas sendo geralmente impostas pelos interesses e mecanismos institucionais dos países doadores, sem atentar para as reais necessidades ao desenvolvimento dos países receptores (CANDEAS, 2012).

Além das soluções apresentadas pelo Brasil aos países receptores não busca atender as necessidades do desenvolvimento destes países, a obrigatoriedade de apresentar o exame de proficiência em língua portuguesa para obtenção da vaga em curso da pós-graduação no Brasil, de acordo com Morosini (2008) caracteriza-se também como uma forma de dominação exercida pelo Brasil para com os demais países do Sul. De acordo com o autor, a língua portuguesa constitui um elemento complexo da estruturação identitária destes estudantes já que, para muitos deles, o português não é língua materna e foi em outra língua que começaram a existir e que adquiriram a sua primeira identidade.

Diante deste contexto, a educação revela-se como um possível instrumento de promoção de liderança brasileira frente aos países do "Sul", de menor desenvolvimento relativo, devendo-se atentar para os riscos de reprodução de um tipo de experiência - a cooperação top-down, colonizadora, não participativa - entre os países com os quais o Brasil possui acordos de cooperação tanto bilateral quanto multilateral (MILANI, 2012; CERVO; BUENO, 2015).

\section{Considerações finais}

Ao longo dos seus mais de 30 anos o PEC-PG se consolidou como uma política de governo cujo objetivo principal era o de desenvolver e auxiliar os países parceiros. Esse auxílio determinado pelo Brasil aos países receptores estabelecem condições e contrapartidas aos países, não sendo possível afirmar que o PEC-PG é um programa de educação internacional totalmente desinteressado. Essas contrapartidas, determinadas pelo governo Brasileiro, caracterizam-se de maneira geral, como ações neocoloniais com o objetivo de exercer o controle e a dominação frente aos países com os quais o Brasil possui acordos de cooperação.

Não por acaso, tais aspectos de dominação e controle nos suscitam a pensar sobre as mesmas características presentes nas relações de cooperação entre nações do Norte para com nações do Sul. A educação nesse sentido, pode ser caracterizada como uma forma atual de dominação para com os demais países, através da obrigatoriedade da língua portuguesa, através da escolha dos programas de pós-graduação que participam, além da obrigatoriedade de apresentação na polícia federal de tempos em tempos.

Dessa maneira, a internacionalização da educação analisada a partir do PEC-PG pode estar apresentando, inclusive, aspectos de formação ou de semiformação que o Bra- 
sil pode estar desempenhando para com seus países parceiros. No sentido de que o Brasil não consulta os países receptores para descobrir suas necessidades de desenvolvimento educacionais, limitando-os a interpretação dos estudantes com suas realidades.

Além disso, o PEC-PG tem-se revelado como um programa extremamente seletivo, devido aos excessos de condicionalidades impostas pelo regulamento do programa $e$ das instituições de ensino superior. Da mesma maneira, algumas das características do programa o distanciam dos princípios basilares da cooperação entre países parceiros. Dessa forma, para que o PEC-PG e a internacionalização da educação no Brasil possa ser caracterizada como inclusiva e cada vez menos neocolonial, o Brasil deve estar disposto a aprender com as experiências de países parceiros considerando que é possível aprender com os países que pertencem ao programa.

\section{Referências}

ALTBACH, Philip; KNIGHT, Jane. The Internationalization of Higher Education: Motivations and Realities. Journal of Studies in International Education. 2007.

BALLESTRIN, L. América Latina e o giro decolonial. Revista Brasileira de Ciência Política, 11, Brasília, 89-117, 2013.

BRASIL. Ministério das Relações Exteriores. Programa de Estudantes-Convênio de Graduação. Brasília: Ministério das Relações Exteriores, 2020a. Disponível em: $<$ http://www.dce.mre.gov.br/PEC/PECPG.php $\geq$. Acesso em: 08 maio 2020.

. Ministério das Relações Exteriores. Como participar do PEC-PG. Protocolo de cláusulas do PEC-PG (2006). Brasília: MRE, 2020b. Disponível em: <http://www.dce.mre.gov.br/PEC/PG/Protocolo_PECPG.pdf> Acesso em: 08 maio 2020.

. Ministério das Relações Exteriores. Programa de Estudantes-Convênio de Graduação. Histórico do PEC PG. Brasília: MRE, 2020c. Disponível em: $<$ http://www.dce.mre.gov.br/PEC/PG/historico.php > Acesso em: 08 maio 2020.

CANDEAS, Alessandro Educação e política externa: a experiência brasileira no Mercosul Educacional. In: Pinheiro, L.\& Milani, C. R. S. (Org.). Política externa brasileira a política das práticas e as práticas da política. Rio de Janeiro: FGV, 2012.

CERVO, Amado Luiz; BUENO, Clodoaldo. História da Política Exterior do Brasil. Brasília: Editora da Universidade de Brasília, 2015, 605 p.

ETCHEVERRY, Daniel A. Sobre Burocracias, Documentos e Sujeitos Imigrantes: Otimização e Flexibilidade na Vivência da Mobilidade. REMHU, Rev. Interdiscip. Mobil. Hum., Brasília, v. 24, n. 47, p. 115-129, 2016.

FANON, F. Os condenados da terra. Juiz de Fora: Editora da UFJF, 2005.

GUIMARAES, Samuel Pinheiro. Desafios e dilemas dos grandes países periféricos: Brasil e Índia. Rev. bras. polít. Int., Brasília, v. 41, n. 1, 1998. 
LEAL, F. G.; MORAES, M. C. B. Política Externa Brasileira, Cooperação Sul-Sul e Educação Superior: o Caso do Programa Estudante-Convênio de Graduação. Educ. Soc., v.39 n.143, 343-359, 2018.

. Decolonialidade como Epistemologia para o Campo Teórico da Internacionalização da Educação Superior. Education Policy Analysis Archives. 26, 29, 2018.

LIMA, M.C.; CONTEL, F.B. Períodos e motivações da Internacionalização da Educação Superior. 5colloque de l'IFBAE, Grenoble, 18 et mai 2009.

LIMA, M. C.; MARANHAO, C. M. Políticas curriculares da internacionalização do ensino superior: multiculturalismo ou semiformação?. Ensaio: aval.pol.públ.Educ., Rio de Janeiro , v. 19, n. 72, p. 575-598, 2011.

MILANI, Carlos R. S. Aprendendo com a história: críticas à experiência da Cooperação NorteSul e atuais desafios à Cooperação Sul-Sul. Cad. CRH, 2012, vol.25, no.65, p.211-231, 2012. MOROSINI, M.C. Internacionalização da educação superior e qualidade. Inovação e qualidade na Universidade. In: AUDY, J.L.; MOROSINI, M.C. (Org.). Innovation and quality in the University. Porto Alegre: EDIPUCS, 2008.

NOGUEIRA, Silvia. Entre o burocrático-legal e a hospitalidade: os estudantes internacionais na Paraíba e a Polícia Federal. Revista Intersecções. v.15 n. 1, 2013

PUENTE, C. A. I. A cooperação técnica horizontal brasileira como instrumento de política externa: a evolução da cooperação técnica com países em desenvolvimento - CTPD- no período 1995-2005. Brasília: FUNAG, 2010.

QUIJANO, A. Colonialidad del poder, eurocentrismo y América Latina In: Lander, Edgardo (org.) La colonialidad del saber: eurocentrismo y ciências sociales. Perspectivas latinoamericanas (Buenos Aires: CLACSO/UNESCO), 2000.

n. 37, p. 4-25, 2002.

Colonialidade, poder, globalização e democracia. Revista Novos Rumos, v. 17,

. Don Quijote y los molinos de viento en América Latina. Revista Electrónica de Estudios Latinoamericanos, Buenos Aires, v. 4, n. 14, 2005.

RANCIÈRE, J. O mestre ignorante - cinco lições sobre emancipação intelectual. Valle, L. (tradução). Editora Autêntica, 2011.

SANTOS, M. Por uma outra globalização: do pensamento único à consciência universal. 13. ed. Rio de Janeiro: Record, 2006.

SILVA, A. Stivalt. A cooperação internacional no CNPq. Porto Alegre: PUCRS, 2007.

Recebido em: 19/07/2020

Aprovado em: 17/10/2020 